\title{
Proceeding
}

Supplementary Issue: Spring Conferences of Sports Science. Costa Blanca Sports Science Events, 14-15 June 2019. Alicante, Spain.

\section{Effects of Shotokan Karate on resilience to bullying in adolescents}

\author{
GIANPIERO GRECO , FRANCESCO FISCHETTI, STEFANIA CATALDI, FRANCESCA LATINO \\ Department of Basic Medical Sciences, Neuroscience and Sense Organs, School of Medicine, University of \\ Study of Bari, Italy
}

\begin{abstract}
Bullying is characterized by power imbalances in relationships, which can lead to negative social consequences. Youth with higher levels of resilience are less likely to engage in aggressive behaviours or be victims of bullying. Karate, a martial art emphasizing respect, self-regulation and health promotion, may be an effective alternative to the anti-bullying failing approach of institutions. Therefore, the purpose of this randomized controlled study was to examine the effect of a 12-week karate based intervention on resilience. 50 students, aged 14-16 years, were randomly assigned to experimental group $(n=25)$ that performed technical Shotokan karate practice, i.e. kihon, kata and kumite (60 min., once per week), or control group $(n=25)$. At baseline and after intervention, the Child and Youth Resilience Measure (CYRM-28) assessed the individual capacities and resources, relationship with primary caregiver, contextual factors and total resilience. The intervention significant improved levels of the overall resilience and resilience sub-factors $(p<0.05)$. The results suggest that psycho-social intervention based on Karate may improve the resilience and well-being of youth and make them less likely to engage in aggressive behaviour or be bullied. Thus, Karate should be considered an effective alternative to the anti-bullying failing approach of the institutions. Keywords: Martial arts; Anti-bullying; Social skills; Wellbeing; Externalizing behaviours.
\end{abstract}

\section{Cite this article as:}

Greco, G., Fischetti, F., Cataldi, C., \& Latino, F. (2019). Effects of Shotokan Karate on resilience to bullying in adolescents. Journal of Human Sport and Exercise, 14(4proc), S896-S905. doi:https://doi.org/10.14198/ihse.2019.14.Proc4.52

Corresponding author. Department of Basic Medical Sciences, Neuroscience and Sense Organs, School of Medicine, University of Study of Bari, Lungomare Starita 1, 70123 Bari (BA). Italy. http://orcid.org/0000-0002-5023-3721

E-mail: gianpiero.greco@uniba.it

Supplementary Issue: Spring Conferences of Sports Science. Costa Blanca Sports Science Events, 14-15 June 2019. Alicante, Spain.

JOURNAL OF HUMAN SPORT \& EXERCISE ISSN 1988-5202

(c) Faculty of Education. University of Alicante

doi:10.14198/jhse.2019.14.Proc4.52

S896 | 2019 | Proc4 | VOLUME 14

C 2019 University of Alicante 


\section{INTRODUCTION}

Bullying is a controversial issue, however there is no standard definition of bullying (Rigby, 2008), and it is difficult to establish a definition inclusive of all bullying behaviours (Lines, 2008). Research suggests bullying can be characterized as (1) a type of aggression (Pellegrini, 2004), (2) systematic and repeated (Olweus, 1993), and (3) based upon an imbalance of power (Bouman et al., 2012). These behaviors occur both directly and indirectly and can lead to negative social consequences. Examples of commonplace power differences in school include being able to physically hurt others, numerical (group) superiority, being more confident or assertive than others, having greater verbal dexterity, having superior social or manipulative skills, and having greater status and corresponding capacity to impose will on others (Rigby, 2008). Antibullying strategies are the main approach addressing bullying in schools (Farrington \& Ttofi, 2009) and claim substantial support to address bullying. However, antibullying approaches are often found to achieve no reduction or observe increases in bullying behaviour (Moore \& Woodcock, 2017; Rigby, 2002).

Resilience is a complex construct (Kaplan, 2006) that is defined as the attainment of positive outcomes, adaptation or developmental milestones in the face of significant adversity, risk, or stress (Goldstein \& Brooks, 2006). Different conceptualisations describe resilience as: (a) a protective process; (b) the interaction of protection and risks; and, (c) a conceptual tool within predictive models (Elias, Parker, \& Rosenblatt, 2006). The operational definition of resilience varies and has included: hardiness, optimism, competence, selfesteem, social-skills, achievement, and absence of pathology in the face of adversity (Prince-Embury, 2007). The research examining the relationship between bullying and resilience is not extensive (Sapouna \& Wolke, 2013), and findings include: (a) students with a strong resilience profile were less likely to engage in aggressive behaviours or be bullied than those who reported fewer developmental strengths (Donnon, 2010); (b) bullying appeared to decrease if social skills were improved in victims, and that nonchalance strategies and emotional regulation were useful (Lisboa \& Killer, 2008); and (c) resilience to bullying was improved if the student had a peer or family member with whom to disclose (Bowes, Maughan, Caspi, Moffitt, \& Arseneault, 2010; Rivers \& Cowie, 2006).

In a recent meta-analysis Harwood, Lavidor, \& Rassovsky (2017) reported that martial arts training had a positive effect on mental health outcomes. Analysis found that martial arts training increases wellbeing and reduces externalizing behaviours in youth, such as aggression, anger, and violence. In addition, martial arts teach self-control and a more positive response to physical challenges, enhance self-esteem, teach and induce greater emotional stability, self-confidence and assertiveness. However, studies examining the psychological effects of martial arts training exhibit significant methodological problems that limit the generalisability of findings (Vertonghen \& Theeboom, 2010). In addition, to date the efficacy of martial arts based social interventions has received little research attention (Hartmann, 2003).

Karate is a martial arts discipline that is widely practiced in the Western world as a form of self-defence and is considered both as a discipline that allows one to achieve physical and mental balance and as a tool for health prevention (Chang, Yeh, Pai, \& Huang, 2018; Douris et al., 2004; Jansen, Dahmen-Zimmer, Kudielka, \& Schulz, 2017; Palermo \& Greydanus, 2011; Qasim, Ravenscroft, \& Sproule, 2014). Accordingly, we may speculate that Karate, a martial art emphasizing respect, self-regulation and health promotion, may be an effective anti-bullying alternative approach (Hartmann, 2003; Macarie \& Roberts, 2010). Thus, the purpose of this study was to examine the effects of 12 weeks of karate based intervention on resilience in adolescents. It was hypothesized that resilience to bullying would improve after intervention. 


\section{MATERIALS \& METHODS}

\section{Research design}

The study was a 12-week high school-based intervention that has been evaluated using a randomized controlled study. All participants and their parents received a complete explanation in advance about the purpose of the experiment, its contents, and safety issues based on the Declaration of Helsinki, and parents provided their informed consent. Data were collected and recorded at baseline (Pre-test) and after 12 weeks (Post-test). After pre-test and randomization, the experimental group received a karate-based intervention program. The control group received the same intervention program after the post-intervention assessment. The design was facilitated by use of a standardised test, which increases the validity and reliability of data as such instruments have been developed and normalised using larger samples and have been piloted to ensure test items actually measure what is intended (Cohen \& Swerdlik, 2005).

\section{Participants}

Fifty adolescents from two high schools in Puglia (Italy) were recruited to participate in the study. The sample consisted of 20 males and 30 females with an age range from 14 to 16 years and a mean age of $14.6 \pm 0.7$ ). The socio-economic status of all participants was reported as high average. Power calculations were conducted to determine the sample size required to detect changes in resilience outcomes resulting from karate training. An a priori power analysis (Faul, Erdfelder, Lang, \& Buchner, 2007) with an assumed type I error of 0.05 and a type $I I$ error rate of 0.10 (90\% statistical power) was calculated and revealed that 46 participants in total would be sufficient to observe medium 'Time x Group' interaction effects. However, to avoid the experimental mortality, that is the loss of participants that could threaten the validity of the research design, more subjects were recruited. Participants were excluded if they had a chronic paediatric disease or had an orthopaedic condition that would limit their ability to perform exercise. The study was conducted from February to April 2019 and all participants completed the post-intervention assessment.

\section{Procedures}

The sampling plan utilised a randomized controlled sample to generate data for the study. The recruitment occurred from schools within an area of close proximity to where one of the researchers was working. The school staff distributed information and consent forms to all students to be recruited and their parents. Participants were verbally reminded that participation was voluntary, that they could discontinue the survey at any point, and that their responses were confidential and anonymous. Participants were instructed regarding (a) not writing their names on the survey, (b) how to respond to rating scales, and (c) how to correct responses. Participants were not provided with definitions of bullying or resilience so as to not bias their responses. Surveys were then provided to participants.

Randomisation into experimental ( $n=25$; age $14.5 \pm 0.7$ years; 10 males and 15 females) and control group $(n=25$; age $14.6 \pm 0.7$ years; 10 males and 15 females) occurred after pre-intervention assessments. Participants were pair-matched based on gender and the randomization was carryout by Research Randomizer, a program published on a publicly accessible official website (www.randomizer.org). The researchers were blinded to this randomisation of intervention and control group allocations. Concurrent martial arts training were exclusion criteria for participation in the study, however previous experience of martial arts training was not an exclusion criterion. Forty-nine participants completed the post-intervention assessment and one female participants of the experimental group did not complete the assessment for unknown reasons. 


\section{Measures}

To evaluate the effects of the intervention program, a standardised psychometric instrument was used: Child and Youth Resilience Measure (CYRM-28) (Liebenberg, Ungar, \& Van de Vijver, 2012; Ungar \& Liebenberg, 2011).

The CYRM-28 is a 28-item instrument that measures various aspects of children's and adolescents' resilience. The scale provided a total resilience scale $(a=0.92)$ and three subscales including an individual capacities and resources scale $(\alpha=0.85)$, relationship with primary caregiver scale $(\alpha=0.84)$, and contextual factors scale $(a=0.82)$. Items are scored on a 5-point Likert scale with $0=$ not at all, $1=a$ little, $2=$ somewhat, $3=$ quite a bit, and $4=a$ lot. The CYRM-28 is designed as a screening tool to explore the resources (individual, relational, and contextual) available that bolster resilience competence in the face of adversity. Individual resources are individual personal skills (e.g., I am aware of my own strengths), individual peer support (e.g., I feel supported by my friends), and individual social skills (e.g., I know where to go in my community to get help). Relational resources are physical caregiving (e.g., My caregiver(s) watch me closely) and psychological caregiving (e.g., I talk to my caregiver(s) about how I feel). Contextual resources are spiritual (e.g., Spiritual beliefs are a source of strength for me), educational (e.g., Getting an education is important to me), and cultural (e.g., I am proud of my ethnic background). Higher scores indicate greater presence of resilience processes.

\section{Intervention program}

The intervention was performed on site at participating schools. The intervention dose was $12 \times 60$ min sessions, once per week for 12 weeks. Each intervention session, co-led by both an exercise professional and psychologist, included:

a) Psychoeducational activities concerning respect, goal-setting, self-concept and self-esteem, courage, resilience, bullying and peer pressure, self-care and caring for others, values, and, optimism and hope;

b) Warm-up activities: exercises including jogging, push ups, sit ups, arm swings, trunk twisting, stride jumping, high knees, skipping leg swings, and backward sprinting;

c) Stretching activities: a variety of stretching exercises were used during the program including achilles' tendon/calf stretches, skier's stretches, quadriceps stretches, hurdler's stretches, straddle stretches, groin stretches, back stretches, and archers;

d) Technical Shotokan karate practice (i.e., kihon): learning a range of basic technical skills, such as body shifting, proper stances, and offensive and defensive technical abilities. Movements must be performed with proper breathing and posture.

In addition, the following activities were alternated during the program:

e) Kata, that is a choreographed sequence of movements consisting of combinations of blocks, punches and kicks, performed as though defending against imaginary opponents;

f) Kumite, that is a match between two opponents in which one symbolically destroys the other with technique and strategy.

Finally, it should be known that aggressive physical contact is not part of Shotokan karate. All sessions were conducted under direct supervision of a psychologist with minimum 10 years of experience, and a black-belt Shotokan karate instructor (2nd Dan) with minimum 8 years of experience and graduate in sports science. 


\section{Statistical analyses}

Statistical analyses were carried out using SAS JMP® Statistics (Version <14.1>, SAS Institute Inc., Cary, NC, USA, 2018). Data are presented as group mean values and standard deviations. The normality of data distributions was checked using a Shapiro-Wilk test. A multivariate analysis of variance (MANOVA) was used to detect differences between the study groups in all baseline variables. A two-way ANOVA (group (experimental/control) $\times$ time (pre/post-intervention)), with repeated measures on the time dimension, was conducted to examine the effect of karate training on all examined variables. When 'Group x Time' interactions reached the level of significance, group-specific post hoc tests (i.e., paired t-tests) were conducted to identify the significant comparisons. Effect sizes (ES) for the pairwise comparisons were determined by Cohen's $d$ and interpreted as small, moderate and large effects defined as $0.20,0.50$, and 0.80 , respectively (Cohen, 1992). Statistical significance was set at $p<0.05$.

\section{RESULTS}

One participant of the experimental group withdrew and thus forty-nine adolescents completed the study. Both groups did not differ significantly at baseline in age, anthropometric characteristics, as well as in the dependent variables $(p>0.05)$. Changes and statistical data in the dependent variables over 12-week intervention program are reported in Table 1.

Table 1. Changes in CYRM-28 resilience scale after 12-week karate-based intervention

\begin{tabular}{lcccccc}
\hline & \multicolumn{2}{c}{$\begin{array}{c}\text { Experimental group } \\
(\mathbf{n}=24)\end{array}$} & \multicolumn{3}{c}{$\begin{array}{c}\text { Control group } \\
(\mathbf{n}=25)\end{array}$} \\
\hline & Baseline & Post-test & $\boldsymbol{\Delta}$ & Baseline & Post-test & $\boldsymbol{\Delta}$ \\
\hline Scales & & & & & & \\
Individual capacities and resources & 2.95 & 3.09 & 0.15 & 3.13 & 3.12 & -0.01 \\
Relationship with primary caregiver & 3.08 & 3.20 & 0.13 & 3.03 & 2.97 & -0.06 \\
Contextual factors & 2.61 & 2.76 & 0.16 & 2.49 & 2.38 & -0.12 \\
Total resilience & 2.88 & 3.02 & 0.14 & 2.88 & 2.82 & -0.06
\end{tabular}

Note: values are presented as mean $( \pm S D) ; \Delta$ : pre- to post-training changes; †Significant 'Group x Time' interaction: significant effect of the intervention $(p<0.05)$. *Significantly different from pre-test $(p<0.01)$.

Group by time interactions were observed for all subscales and total resilience $(p<0.05)$. After 12 weeks, the experimental group showed increased scores than control group with statistically significant within-group changes for: Individual capacities and resources $(p<0.001, d=0.89)$, Relationship with primary caregiver $(p=0.006, d=0.59)$, Contextual factors $(p=0.004, d=0.63)$ and Total resilience $(p<0.001, d=1.18)$.

\section{DISCUSSION}

The purpose of this study was to examine the effects of 12 weeks of karate based intervention on resilience in adolescents. The results provided valid and reliable evidence that a psychosocial intervention based on Shotokan Karate could be an effective alternative method to improve resilience and wellbeing in youth (Hartmann, 2003; Macarie \& Roberts, 2010). In addition, interventions using this approach should promote an individual's ability to cope with the effects of bullying. Significant improvements were found in experimental group for levels of the overall resilience and resilience sub-factors, whereas control group showed no significant changes. Therefore, our hypothesis has been confirmed and the results agree with previous studies showing the effectiveness of karate in promoting physical and mental balance and in preventing 
health (Chang et al., 2018; Douris et al., 2004; Jansen et al., 2017; Palermo \& Greydanus, 2011; Qasim et al., 2014).

For the intervention group, positive changes in resilience showed a moderate to large effect size for all subscales and total resilience. This is an important achievement because students who report higher levels of resilience may be less likely to engage in aggressive behaviour or be bullied (Donnon, 2010; Lisboa \& Killer, 2008; Rigby, 2008). Significant improved relationships with primary caregivers has been particularly important, as family factors, including warm relationships and positive home environments, are associated with increased resilience to bullying (Bowes et al., 2010). It has been shown that resilience to bullying behaviours is improved when people can reveal their experiences to a family member (Rivers \& Cowie, 2006). Furthermore, significant improvements in the resources individual, relational and contextual available support resilience competence in the face of adversity (Fischetti, Cataldi, Di Terlizzi, \& Greco, 2019; Goldstein \& Brooks, 2006; Kaplan, 2006; Naglieri \& LeBuffe, 2006; Prince-Embury, 2007) and, thus, bullying (Bowes et al., 2010; Donnon, 2010; Lisboa \& Killer, 2008; Rivers \& Cowie, 2006; Sapouna \& Wolke, 2013).

The effectiveness of Karate Shotokan based psychosocial interventions on mental wellbeing, emotional stability, self-control and ability to cope with adversity is supported by well-established scientific theories. Externalizing and antisocial behaviours amongst youth are of pressing concern and considered a major public health problem (Krug, Mercy, Dahlberg, \& Zwi, 2002). However, it has been suggested that motor and sport activities improve psychological (Fischetti, Latino, Cataldi, \& Greco, 2019) and physical fitness (Fischetti \& Greco, 2017; Fischetti, Vilardi, Cataldi, \& Greco, 2018; Fischetti, Cataldi, \& Greco, 2019; Greco, Cataldi, \& Fischetti, 2019), cognitive functions and, specifically, executive functions in youth (Diamond \& Lee, 2011), as well as externalizing behaviors (Zhou et al., 2007). A novel intervention for the externalizing behaviors treatment is provided by martial arts and, in particular, by Karate. The more advanced a student becomes in the traditional martial arts, the lower his or her aggression levels are reported on a range of measures (Nosanchuk \& MacNeil, 1989; Reynes \& Lorant, 2002). While martial arts appear to attract those children that have higher aggressive tendencies, it seems that throughout the training process assaultive hostility levels drop to below levels of those initially demonstrating normal hostility levels (Daniels \& Thornton, 1990; Ziaee, Lotfian, Amini, Mansournia, \& Memari, 2012). Indeed, learning to understand one's boundaries, developing self-control, and physically integrating mind and body can have deep psychological benefits (Jansen \& Dahmen-Zimmer, 2012; Weiser, Kutz, Kutz, \& Weiser, 1995). Nevertheless, previous review of the effect of martial arts of socio-psychological variables (Vertonghen \& Theeboom, 2010) demonstrated the variability of research pertaining to the effect of martial arts on externalizing behaviours and highlighted the need for more extensive research.

Some limitations may limit the results of the current study. Given that the study only examined participants from two high-school, the findings should be interpreted cautiously, as they may be the result of a localized effect. In addition, as noted in the literature review, both bullying and resilience are complex constructs and lack an agreed academic definition. This presents questions in terms of whether the definitions used in the current study adequately operationalise the constructs. Future research should expand the definition of resilience and bullying.

However, this study has some strengths, i.e. it proposes an alternate approach to educational policy and suggests that instead of focusing resources towards eliminating bullying behaviours, policy should focus on promoting mental health through developing wellbeing. Future research should examine the karate based intervention program's effects on different population samples. Consideration should be given to implementing the intervention as a universal program with primary school students, selecting specific 
populations such as participants diagnosed with (a) mental health issues such as anxiety and depression, (b) Autism Spectrum Disorder, (c) intellectual disability, and (d) behavioural disorders such as Oppositional Defiant Disorder, and participants that have experienced violent incidents including domestic and sexual violence. Positive effects of Karate have already been documented in reducing stereotypy in autism (Bahrami, Movahedi, Marandi, \& Abedi, 2012), improving quality of life in schizophrenia (Hasson-Ohayon, Kravetz, Roe, Rozencwaig, \& Weiser, 2006), and increasing emotional mental state in the elderly (Jansen \& Dahmen-Zimmer, 2012), thereby adding further evidence to the wellbeing enhancing mechanisms of the martial arts across a range of populations.

\section{CONCLUSIONS}

In summary, the findings suggested that a psychosocial intervention based on a traditional martial art, such as Karate Shotokan, may improve the resilience and wellbeing of adolescents, and make them less likely to engage in aggressive behaviour or be bullied. Evidence supports that anti-bullying policies are inconsistent; therefore, Karate should be considered as an alternative practice to improve individual ability to cope with the effects of bullying and an effective alternative to the anti-bullying failing approach of the institutions. Future research should develop a professional learning program for teachers to facilitate similar programs which could be embedded within a physical education curriculum.

\section{FUNDING}

No sources of funding were used to assist in the preparation of this manuscript.

\section{CONFLICT OF INTEREST STATEMENT}

The authors declared no potential conflicts of interest with respect to the research, authorship, and/or publication of this article.

\section{AUTHORS' CONTRIBUTION}

GG designed the study, carried out the statistical analysis, interpreted the data, wrote and revised the manuscript. FF designed the study, interpreted the data, wrote and revised the manuscript. SC collected and interpreted the data. FL collected and interpreted the data and revised the manuscript. All authors contributed intellectually to the manuscript, and all authors have read the manuscript and approved the submission.

\section{REFERENCES}

Bahrami, F., Movahedi, A., Marandi, S. M., \& Abedi, A. (2012). Kata techniques training consistently decreases stereotypy in children with autism spectrum disorder. Research in Developmental Disabilities, 33(4), 1183-1193. https://doi.org/10.1016/..ridd.2012.01.018

Bouman, T., van der Meulen, M., Goossens, F., Olthaf, T., Vermande, M., \& Aleva, E. (2012). Peer and self-reports of victimization and bullying: Their differential association with internalizing problems and social adjustment. Journal of School Psychology, 50(6), 759-774. https://doi.org/10.1016/i.jsp.2013.04.001

Bowes, L., Maughan, B., Caspi, A., Moffitt, T., \& Arseneault, L. (2010). Families promote emotional and behavioral resilience to bullying: Evidence of an environmental effect. Journal of Child Psychology and Psychiatry, 51(7), 809-814. https://doi.org/10.1111/i.1469-7610.2010.02216.x 
Chang, Y. C., Yeh, T. M., Pai, F. Y., \& Huang, T. P. (2018). Sport Activity for Health!! The Effects of Karate Participants' Involvement, Perceived Value, and Leisure Benefits on Recommendation Intention. International journal of environmental research and public health, 15(5), 953. https://doi.org/10.3390/ijerph15050953

Cohen, J. (1992). A power primer. Psychological bulletin, 112(1), 155-159.

Cohen, R., \& Swerdlik, M. (2005). Psychological testing and assessment. Boston: McGraw Hill.

Daniels, K., \& Thornton, E. W. (1990). An analysis of the relationship between hostility and training in the martial arts. Journal of Sports Sciences, 8(2), 95-101. https://doi.org/10.1080/02640419008732137

Diamond, A., \& Lee, K. (2011). Interventions shown to aid executive function development in children 4 to 12 years old. Science, 333, 959-964. https://doi.org/10.1126/science.1204529

Donnon, T. (2010). Understanding how resiliency development influences adolescent bullying and victimization. Canadian Journal of School Psychology, 25(1), 101-113. https://doi.org/10.1177/0829573509345481

Douris, P., Chinan, A., Gomez, M., Aw, A., Steffens, D., \& Weiss, S. (2004). Fitness levels of middle aged martial art practitioners. British Journal of Sports Medicine, 38(2), 143-147. https://doi.org/10.1136/bjsm.2002.001768

Elias, M., Parker, S., \& Rosenblatt, J. (2006). Building educational opportunity. In S. Goldstein \& R. Brooks (Eds.), Handbook of resilience in children (pp. 315-336). New York: Springer. https://doi.org/10.1007/0-306-48572-9_19

Farrington, P., \& Ttofi, M. (2009). School-based programs to reduce bullying and victimization. Campbell Systematic Review, Oslo: Campbell Collaboration. https://doi.org/10.4073/csr.2009.6

Faul, F., Erdfelder, E., Lang, A. G., \& Buchner, A. (2007). G* Power 3: A flexible statistical power analysis program for the social, behavioral, and biomedical sciences. Behavior research methods, 39(2), 175191. https://doi.org/10.3758/bf03193146

Fischetti, F., Cataldi, S., Di Terlizzi, P.G., \& Greco, G. (2019). Multilateral methodology in physical education improves coping skills, resilience and physical fitness in drug addicts. Journal of Human Sport And Exercise. https://doi.org/10.14198/ihse.2020.152.11

Fischetti, F., \& Greco, G. (2017). Multilateral methods in Physical Education improve physical capacity and motor skills performance of the youth. Journal of Physical Education and Sport, 17(Suppl 4), 2161-2168. https://doi.org/10.7752/jpes.2017.s4223

Fischetti, F., Cataldi, S., \& Greco, G. (2019). A Combined Plyometric and Resistance Training Program Improves Fitness Performance in 12 to 14-years-old Boys. Sport Sciences for Health. https://doi.org/10.1007/s11332-019-00560-2

Fischetti, F., Latino, F., Cataldi, S., \& Greco, G. (2019). Gender Differences in Body Image Dissatisfaction: The Role of Physical Education and Sport. Journal of Human Sport And Exercise. https://doi.org/10.14198/ihse.2020.152.01

Fischetti, F., Vilardi, A., Cataldi, S., Greco, G. (2018). Effects of Plyometric Training Program on Speed and Explosive Strength of Lower Limbs in Young Athletes . Journal of Physical Education and Sport, 18, 2476-2482. https://doi.org/10.7752/jpes.2018.04372

Goldstein, S., \& Brooks, R. (2006). Why study resilience? In S. Goldstein \& R. Brooks (Eds.), Handbook of resilience in children (pp. 3-16). New York: Springer. https://doi.org/10.1007/0-306-48572-9_1

Greco, G., Cataldi, S., \& Fischetti, F. (2019). Effectiveness of a Short After-School Intervention on Physical Fitness in School-Aged Children. Journal of Theories and Research in Education.14(1), 143-164. https://doi.org/10.6092/issn.1970-2221/9217

Hartmann, D. (2003). Theorizing sport as social intervention: A view from the grassroots. Quest, 55, $118-$ 140. https://doi.org/10.1080/00336297.2003.10491795 
Harwood, A., Lavidor, M., \& Rassovsky, Y. (2017). Reducing aggression with martial arts: A metaanalysis of child and youth studies. Aggression and violent behavior, 34, 96-101. https://doi.org/10.1016/i.avb.2017.03.001

Hasson-Ohayon, I., Kravetz, S., Roe, D., Rozencwaig, S., \& Weiser, M. (2006). Qualitative assessment of verbal and non-verbal psychosocial interventions for people with severe mental illness. Journal of Mental Health, 15(3), 343-353. https://doi.org/10.1080/09638230600700847

Jansen, P., \& Dahmen-Zimmer, K. (2012). Effects of cognitive, motor, and karate training on cognitive functioning and emotional well-being of elderly people. Frontiers in Psychology, 3, 40-41. https://doi.org/10.3389/fpsyg.2012.00040

Jansen, P., Dahmen-Zimmer, K., Kudielka, B. M., \& Schulz, A. (2017). Effects of karate training versus mindfulness training on emotional well-being and cognitive performance in later life. Research on aging, 39(10), 1118-1144. https://doi.org/10.1177/0164027516669987

Kaplan, H. (2006). Understanding the concept of resilience. In S. Goldstein \& R. Brooks (Eds.), Handbook of resilience in children (pp. 39-48). New York: Springer.

Krug, E.G., Mercy, J.A., Dahlberg, L.L., \& Zwi, A.B. (2002). World report on violence and health. Lancet, 360(9339), 1083-88. https://doi.org/10.1016/s0140-6736(02)11133-0

Liebenberg, L., Ungar, M., \& Van de Vijver, F. (2012). Validation of the child and youth resilience measure-28 (CYRM-28) among Canadian youth. Research on Social Work Practice, 22(2), 219226. https://doi.org/10.1177/1049731511428619

Lines, D. (2008). The bullies: Understanding bullies and bullying. London: Jessica Kingsley. https://doi.org/10.1177/13591045090140031008

Lisboa, C., \& Killer, S. (2008). Coping with peer bullying and resilience promotion: Data from Brazilian at-risk children. International Journal of Psychology, 43, 711.

Macarie, I., \& Roberts, R. (2010). Martial arts and mental health. Contemporary Psychotherapy, 2, 1-4.

Moore, B., \& Woodcock, S. (2017). Resilience to bullying: Towards an alternative to the anti-bullying approach. Educational Psychology in Practice, 33(1), 65-80. https://doi.org/10.1080/02667363.2016.1233488

Naglieri, J., \& LeBuffe, P. (2006). Measuring resilience in children. In S. Goldstein \& R. Brooks (Eds.), Handbook of resilience in children (pp. 107-123). New York: Springer. https://doi.org/10.1007/0-306$\underline{48572-9 \_8}$

Nosanchuk, T. A., \& MacNeil, M. L. C. (1989). Examination of the effects of traditional and modern martial arts training on aggressiveness. Aggressive Behavior, 15, 153-159. https://doi.org/10.1002/10982337(1989)15:2<153::aid-ab2480150203>3.0.c0;2-v

Olweus, D. (1993). Bullying at school. Oxford: Blackwell.

Palermo, M.T., \& Greydanus, D.E. (2011). Social cognition, executive dysfunction and neuro-behavioral karate: Alternative medicine or psychomotor treatment? International Journal of Child and Adolescent Health, 4(3), 213-220.

Pellegrini, A. (2004). Bullying during the middle school years. In C. Saunders \& G. Pyne (Eds.), Bullying: Implications for the classroom (pp. 177-202). New York: Elsevier Academic Press. https://doi.org/10.1016/b978-012617955-2/50014-x

Prince-Embury, S. (2007). Resilience scales for children and adolescents: A profile of personal strengths. Minneapolis: Pearson.

Qasim, S., Ravenscroft, J., \& Sproule, J. (2014). The effect of karate practice on self-esteem in young adults with visual impairment: A case study. Australian Journal of Educational \& Development Psychology, 14, 167-185.

Reynes, E., \& Lorant, J. (2002). Karate and aggressiveness among eight-year-old boys. Perceptual and Motor Skills, 94, 1041-1042. https://doi.org/10.2466/pms.2002.94.3.1041 
Rigby, K. (2002). A meta-evaluation of methods and approaches to reducing bullying in pre-schools and early primary school in Australia. Canberra: Commonwealth Attorney-General's Department. https://doi.org/10.1037/e669792010-001

Rigby, K. (2008). Children and bullying: How parents and educators can reduce bullying at schools. Carlton, Victoria: Blackwell.

Rivers, I., \& Cowie, H. (2006). Bullying and homophobia in UK schools: A perspective on factors affecting resilience and recovery. Journal of Gay \& Lesbian Issues in Education, 3(4), 11-43. https://doi.org/10.1300/j367v03n04_03

Sapouna, M., \& Wolke, D. (2013). Resilience to bullying victimization: The role of individual, family and peer characteristics. Child Abuse and Neglect, 37(11), 997-1006. https://doi.org/10.1016/j.chiabu.2013.05.009

Ungar, M., \& Liebenberg, L. (2011). Assessing resilience across cultures using mixed methods: Construction of the child and youth resilience measure. Journal of Mixed Methods Research, 5(2), 126-149. https://doi.org/10.1177/1558689811400607

Vertonghen, J., \& Theeboom, M. (2010). The social-psychological outcomes of martial arts practise among youth: A review. Journal of Sports Science and Medicine, 9(4), 528-537.

Weiser, M., Kutz, I., Kutz, S. J., \& Weiser, D. (1995). Psychotherapeutic aspects of the Martial Arts. American Journal of Psychotherapy, 49(1), 118-127. https://doi.org/10.1176/appi.psychotherapy.1995.49.1.118

Zhou, Q., Hofer, C., Eisenberg, N., Reiser, M., Spinrad, T. L., \& Fabes, R. A. (2007). The developmental trajectories of attention focusing, attentional and behavioral persistence, and externalizing problems during school-age years. Developmental Psychology, 43, 369-385. https://doi.org/10.1037/0012$\underline{1649.43 .2 .369}$

Ziaee, V., Lotfian, S., Amini, H., Mansournia, M.A., \& Memari, A.H. (2012). Anger in adolescent boy athletes: A comparison among judo, karate, swimming and non-athletes Iranian Journal of Pediatrics, 22(1), 9-14.

\section{(2) $\mathbb{D} \Theta \Theta$}

This work is licensed under a Attribution-NonCommercial-NoDerivatives 4.0 International (CC BY-NC-ND 4.0). 